\title{
Iğdır yöresinde yetiştirilen 'Teberze' ve 'Ağerik' kayısı (Prunus armeniaca L.) çeşitlerine ait detaylı meyve kalite içerikleri
}

\section{Detailed fruit quality contents of 'Teberze' and 'Ağerik' apricot (Prunus armeniaca L.) cultivars grown in Iğdır province}

\author{
Mehmet Ali SARIDAŞ ${ }^{1 *}$ iD, Erdal AĞÇAM ${ }^{2}$ iD \\ ${ }^{1}$ Çukurova Üniversitesi Ziraat Fakültesi Bahçe Bitkileri Bölümü, 01330 Adana, Türkiye \\ ${ }^{2}$ Çukurova Üniversitesi Ziraat Fakültesi Gıda Mühendisliği Bölümü, 01330 Adana, Türkiye \\ ${ }^{1}$ https://orcid.org/0000-0002-5180-1874; ${ }^{2}$ https://orcid.org/0000-0002-2677-2020
}

\section{To cite this article:}

Sarıdaş, M.A. \& Ağçam, E. (2021). Iğdır yöresinde yetiştirilen 'Teberze' ve 'Ağerik' kayısı (Prunus armeniaca L.) çeşitlerine ait detaylı meyve kalite içerikleri. Harran Tarım ve Gıda Bilimleri Dergisi, 25(2): 214-224.

DOI: 10.29050/harranziraat.911823

Address for Correspondence: Mehmet Ali SARIDAŞ e-mail:

masaridas@gmail.com

Received Date: 08.04.2021

Accepted Date:

21.05.2021

(c) Copyright 2018 by Harran University Faculty of Agriculture. Available on-line at www.dergipark.gov.tr/harranziraat

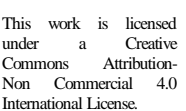

\section{Öz}

Ülkemiz kayısı türü için dünya içerisinde çeşitlilik ve üretim miktarı bakımından önemli bir konuma sahiptir. Ülkemizdeki bu çeşitlilik, yetiştiricilik yapılan illere özgü genotiplerin zamanla seçilip, çoğaltılmasını sağlamıştır. Bu çeşitlilik insan beslenmesinde önemli besin içeriklerinin çeşit bazında oldukça farklı olduğunu göstermektedir. Bu çalışmada Iğdır ilinde Şalak kayısı çeşidinden sonra önemli düzeyde yetiştiriciliği yapılan 'Teberze' ve 'Ağerik' kayısı çeşitlerinde meyve kalitesini etkileyen antioksidan aktivitesi, toplam fenol, toplam karotenoid içerikleri yanında bireysel fenolikler ve karotenoidler, tüketim kalitesini etkileyen bireysel şeker ve asit miktarları incelenmiştir. Sonuç olarak genetik yapının oldukça belirleyici olduğu; Teberze çeşidinde antioksidan aktivitesi, toplam fenol, toplam karotenoid içeriği yanında bireysel fenolik ve karotenoid içeriklerinin de önemli ölçüde yüksek olduğu belirlenmiştir. Çalışmada her iki çeşit içinde; temel karotenoid pigmentinin $\beta$ - karoten, temel fenolik madde ise; Teberze için gallik asit iken, Ağerik'de kateşinin baskın olduğu saptanmıştır. Çeşitlerin tadını etkileyen şeker ve asit bileşenlerinden malik asit dışında diğerlerinin önemli düzeyde farklı olduğu belirlenmiştir. Ağerik çeşidinde glikoz, fruktoz ve sorbitol içeriği önemli ölçüde yüksek iken, tadı etkileyen diğer bileşiklerin Teberze çeşidinde önemli ölçüde yüksek bulunmuştur. Sonuç olarak, Iğdır ilinde yaygın olarak yetiştirilen bu çeşitlerin melezleme çalışmaları için önemli birer gen kaynağı olduğu belirlenmiştir.

Anahtar Kelimeler: Antioksidan aktivite, Fenolik ve karotenoid bileşenler, Genetik kaynak, Organik asit, Şeker

\section{ABSTRACT}

Turkey has taken important place for apricot species in terms of diversity and production amount in the World. This diversity in Turkey is provided selection and propagation of this superior genotype that specifically to that region by time. This diversity, it is shown that there is quite difference in the composition of nutrients content of cultivars whose importance in human nutrition. With this study, antioxidant activity, total phenol, total carotenoid content, as well as individual phenolics and carotenoids, individual sugar and acid amounts which effects the consuming quality were investigated in 'Teberze' and 'Ağerik' apricot cultivars, which are grown significantly higher after the 'Şalak' apricot cultivar in Iğdır province. As a result, the genetic structure is quite determinant; the antioxidant activity, total phenol, total carotenoid content, and the individual phenolic and carotenoid contents were found to be significantly higher in 'Teberze' cultivar. In both varieties; the dominant carotenoid pigment is $\beta$-carotene. On the other hands, while the main phenolic compound was gallic acid for Teberze, catechin was dominant in 'Ağeriği'. Moreover, the sugar and acid compositions, which affect the taste of the cultivars, were determined significantly different except for malic acid. While the glucose, fructose and sorbitol was significantly higher in 'Ağerik', other compounds affecting the taste were found to be significantly higher in the 'Teberze' cultivar. As a result, these cultivars, widely grown in Iğdır province, are important genetic resource for cross-breeding researches.

Key Words: Antioxidant activity, Phenolic and carotenoid compounds, Genetic resource, Organic acid, Sugar 


\section{Giriş}

Kayısı (Prunus armeniaca) Rosaceae familyası ve Prunoideae alt familyasına aittir. Kayısı çeşitleri; Merkez Asya, İran-Kafkasya, Avrupa ve Dzhungar-Zailing olmak üzere 4 eko-coğrafik gruba ayrılmaktadır (Kostina, 1969). Asıl orijini olan Çin'de kayısı yetiştiriciliğinin tarihi en az 5000 yılı kapsamaktadır (He ve ark., 2007; Yuan ve ark., 2007). Avrupa kayısı yetiştiriciliği ise Roma imparatorluğunun toprakları üzerinde küçük meyve bitkisi olarak İsa'nın doğumundan sonraki birinci yüzyıldan beri yapılmaktadır. (Faust, 1989). Aynı araştırıcı, iri meyveye sahip olan çeşitlerin oluşturulmasında Türkler tarafından getirilen genotiplerin Macaristan'da 17. yüzyılda seçilmesiyle oluşturduğu hipotezini sunmaktadır. Çin, Merkez Asya ve İran-Kafkasya bölgeleri, Merkez Avrupa ile kıyaslandığında halen yabani kayısı çeşitliliği için önemli bir limandır (Akpınar ve ark., 2010; Yılmaz ve Gürcan, 2012). İran-Kafkasya bölgesinden Avrupa'ya doğru gidildikçe genetik çeşitlilik azalma eğilimindedir (Bourguiba ve ark., 2012). Günümüzde kayısı temel olarak Akdeniz havzası, eski Sovyetler birliği ülkeleri, İran, Çin, Japonya yanında Güney Afrika ve $A B D$ gibi ülkelerin ılıman bölgelerinde de yetiştirilmektedir. Türkiye'nin 2020 yılı kayısı üretim miktarı 833.398 ton iken Iğdır ilinin bu üretimdeki payı 40.207 ton ile yaklaşık \%5 olarak belirlenmiştir (Anonim, 2021). Bununla birlikte, kayısı yetiştiriciliğinde Şalak \%85 üretim düzeyi ile ilk sırayı alırken, geri kalan üretim Teberze, Ağerik (Teyvent) ve Ordubat ile gerçekleştirilmektedir (Asma, 2000). Ayrıca, ülke genelinde 2020 yılında ağaç başına verim değeri $47 \mathrm{~kg}$ iken, Iğdır ilinde bu değer 159 kg olarak belirlenmiştir (Anonim, 2021). Yüksek verimin temel nedeni; kullanılan çeşitlerin o yöreden seleksiyon yöntemiyle seçilmiş olmaları ve bölgenin kayısı yetiştiriciliği için oldukça uygun olan mikroklima bir alan olması gibi nedenlerden kaynaklandığı düşünülmektedir.

Birçok ıslah programında; yeme kalitesi iyi, aromalı ve sert, yüksek şeker içeriği, büyük boyut, çekici meyve rengi, hasat sezonunu genişletmek, şarkaya dayanımı sağlamak gibi amaçlar yer almaktadır (Audergon, 1993; Bassi ve ark., 1993; Ledbetter ve ark., 2006; Karayiannis ve ark., 2008). Bununla birlikte ülkemizde ticari olarak yetiştirilen kayısı çeşitlerinin büyük çoğunluğu seleksiyon yöntemiyle elde edilmekle birlikte, melezleme ıslahıyla çeşit elde etmeye yönelik çalışmalar da yapılmaktadır (Asma ve ark., 2017; Asma ve ark., 2018; Çuhacı ve ark., 2021).

Kayısı meyveleri içerisindeki fenolik bileşiklerden dolayı bağışıklık sistemini uyarma, iltihaplanmaya karşı koruma, antioksidan özelliklerinden dolayı insan sağlığı üzerine yararlı etkilere sahiptir (Madrau ve ark., 2009). Meyve kalitesi üzerine etkili bileşikler arasında; polifenoller en fazla miktarda bulunan doğal antioksidanlardır. Bunlar sağlığa faydalı önemli besinler olması yanında gıda sanayisi için doğal üretim kaynağı potansiyeline sahiptirler (GómezMartínez ve ark., 2021). Fitokimyasalların içerik ve miktarları gün ışığına, toprağa, mevsim, olgunlaşma durumuna, tarım bölgesine ve meyve çeşidi gibi değişik faktörlere bağııdır (Harris, 1977). Yine bu çalışmada toplam polifenol içeriğinin genotipe ve yıla bağlı olarak önemli düzeyde değişirken; miktarsal olarak neoklorojenik asit, klorojenik asit ve flovonoidlerden rutin ve kuersetin-3-glukuronid bileşikleri yüksek düzeyde tespit edilmiştir (Gómez-Martínez ve ark., 2021). Iğdır ilinin de içinde yer aldığı Aras vadisinde yapılan başka bir çalışmada 26 yabani kayısı genotipi ile bölgede yaygın olarak yetiştirilen Aprikoz (Şalak) kayısı çeşidinde meyve kalite parametrelerinin oldukça değişken olmakla birlikte, yabani genotiplerin önemli gen kaynağı olduğu bildirilmiştir (Geçer ve ark., 2020). Genotip etkisi yanında hasat edilen yıl ve yapılan farklı gübre uygulamalarının meyve kalite parametrelerini etkilediği bildirilmiştir (Karlıdağ ve ark., 2021).

Çalışmamızda yer alan bu genotipler daha önce farklı çalışmalarda pomolojik ve genel kalite parametreleri bakımından incelenmiştir (Özyörük ve Güleryüz, 1992; Muradoğlu ve ark., 2011; Altıkat ve Temiz, 2019). Bu çalışma ile ülkemiz için önemli gen kaynağı olabilme özelliğine sahip 'Teberze' ve 'Ağerik' kayısı çeşitlerinde bildiğimiz 
kadarıyla ilk kez meyve kalite parametreleri (bireysel polifenoller ve karotenoidler) detaylı bir şekilde ortaya çıkarılması amaçlanmıştır.

\section{Materyal ve Metot}

\section{Materyal}

Çalışmada materyal olarak ığdır ilinde yetiştirilen 'Teberze' ve 'Ağerik' çeşidine ait ticari olgunluğa ulaşan meyveler kullanılmıştır. Çiftçi koşullarında yetiştirilen 10-15 yaşındaki sağlıklı olan ağaçlardan 3 Temmuz 2020 tarihinde 'Teberze' çeşidi hasat edilirken, 'Ağerik' çeşidi ise 16 Temmuz 2020 tarihinde meyveler hasat edilerek Çukurova Üniversitesine gönderilmiştir. Alınan meyveler analiz tarihine kadar $-80{ }^{\circ} \mathrm{C}$ 'de aynı Üniversitenin Gıda Mühendisliği bölümünde tutulmuştur.

\section{Metot}

\section{Toplam karotenoid analizi}

Kayısı örneklerinin toplam karotenoid miktarları için Lee ve ark. (2001)'nın geliştirdiği yöntem temel alınmıştır. Bu yöntemde $5 \mathrm{~g}$ kayısı pulpu teflon bir tüpe aktarılarak üzerine $10 \mathrm{~mL}$ ekstraksiyon

çözeltisi (hekzan:aseton:metanol/50:25:25, \%0.1 BHT içerikli) ilave edilmiştir. Bu işlemi takiben bir karıştırma uygulandıktan hemen sonra santrifüjleme işlemine (4000 rpm, 10 dakika, $4{ }^{\circ} \mathrm{C}$ ) geçilmiştir. Santrifüjleme sonrası vakit kaybetmeden $450 \mathrm{~nm}$ 'de absorbans ölçümü gerçekleştirilmiştir.

Toplam karotenoid $\left(\frac{m g}{100 g}\right)=\frac{\text { Absorbans } * S F}{E^{\frac{1}{2}}} * 1000$

SF: Seyreltme faktörü

$\mathrm{E}^{1 / 2}=$ Ekstinksiyon katsayısı (2505)

\section{Antioksidan aktivite analizi}

Antioksidan aktivite (AA) analizinde Klimczak ve ark. (2007) tarafından önerilen spektrofotometrik yöntemde bazı değişiklikler yapılarak kayısı ekstraktı için uygun hale getirilmiştir. Çalışmada 5 g kayısı 50 mL'ye \%80'lik metanol ile tamamlanmış ve santrifüj işlemi ( $4{ }^{\circ} \mathrm{C}, 10$ dakika $6000 \mathrm{rpm}$ ) gerçekleştirilmiştir. Antioksidan aktivite analizi için $100 \mu \mathrm{L}$ ekstrakt alınıp, üzerine $3000 \mu \mathrm{L}$ 1,1-difenil2-pikrilhidrazil (DPPH*; \%80 metanolda $0.05 \mathrm{~g} \mathrm{~L}^{-1}$ ) ilave edilmiştir. Bunu takiben örnekler karıştırılmış ve reaksiyonun dengeye gelmesi için karanlıkta bir saat bekletilmiştir. Bu sürenin sonunda örneklerin absorbansı \%80 metanol çözeltisine karşı dalga boyu $515 \mathrm{~nm}$ 'ye ayarlı spektrofotometrede (Perkin Elmer Lambda 25 UV/VIS, Massachusetts, USA, 2005) ölçülmüştür. Örneklerin AA değerleri aşağıdaki eşitlik kullanılarak DPPH'ın inhibisyon \%'si olarak ifade edilmiştir.

$A A(\%)=\frac{A_{K}-A_{\ddot{O}}}{A_{K}} \times 100$

$A_{\kappa}$ : Kontrolün absorbans değeri

Aö: Örneğin absorbans değeri

$\mathrm{DPPH}^{* \prime}$ in inhibisyon yüzdeleri belirlendikten sonra aynı yöntemle oluşturulan troloks eşdeğer grafiği (50-1000 $\mathrm{mg} \mathrm{L}^{-1}$ ) kullanılarak örneklerin $\mathrm{DPPH}^{*}$ inhibisyon yüzdeleri eşdeğer troloks değerlerine dönüştürülmüştür.

\section{Toplam fenolik içeriği analizi}

Kayısılar yüksek devirli parçalayıcıda parçalandıktan sonra elde edilen karışımdan $5 \mathrm{~g}$ örnek $50 \mathrm{~mL}$ 'lik santrifüj tüpüne aktarılmış ve üzerine $45 \mathrm{~mL} \% 80$ 'lik $\mathrm{MeOH}$ çözeltisinden ilave edilmiştir. Santrifüj tüpü vortekste 30 saniye karıştırıldıktan sonra santrifüj (6000 rpm, $4{ }^{\circ} \mathrm{C}, 10$ dakika) işlemine geçilmiştir. Berrak kısımdan 100 $\mu \mathrm{L}$ alınıp üzerine $200 \mu \mathrm{L}$ Folin-Ciocalteau, $3000 \mu \mathrm{L}$ saf su eklenip 10 dakika bekletilmiştir. Süre sonunda çözelti üzerine $100 \mu \mathrm{L} \% 20^{\prime}$ lik $\mathrm{Na}_{2} \mathrm{CO}_{3}$ eklenip 2 saat karanlık bir ortamda bekletildikten sonra Perkin Elmer Lambda 25 UV/VIS spektrofotometre' de (Massachusetts, USA, 2005) $765 \mathrm{~nm}$ dalga boyunda şahide karşı okunmuştur. Örneklerde ölçülen absorbans değerinin gallik asit cinsinden eşdeğeri olan fenolik bileşik miktarı, gallik asit ile hazırlanmış olan standart eğrinin denkleminden hesaplanmıştır. Örneklerdeki toplam fenolik madde miktarı ' $m g$ gallik asit $\mathrm{kg}^{-1}$ ' cinsinden ifade edilmiştir (Abdullakasim ve ark., 2007). 
Şeker-organik asitlerin analizi

Analiz için kayısılar öncelikle yüksek devirli parçalayıcıda parçalanmıştır. Bu karışımdan $1 \mathrm{~g}$ alınıp $15 \mathrm{~mL}$ 'lik santrifüj tüpüne aktarılmış ve üzerine ağırlık 10 gram oluncaya kadar ultra saf su ilave edilmiştir. Tüpler karıştırıldıktan sonra santrifüj (6000 rpm, $4{ }^{\circ} \mathrm{C}, 10$ dakika) işlemine yapılmıştır. Elde edilen üstteki berrak kısım alınıp, $0.45 \mu m^{\prime}$ lik naylon filtrelerden geçirilerek enjeksiyon şişeleri hazırlanmıştır. Daha sonra elde edilen ekstrakt doğrudan HPLC-DAD-RID sistemine (Shimadzu, LC-20AT, Kyoto, Japonya, 2006) enjekte edilmiştir. Mobil faz olarak $5 \mathrm{mM}$ $\mathrm{H}_{2} \mathrm{SO}_{4}$ çözeltisi kullanılmıştır. Örneklerdeki şeker içeriği g $100 \mathrm{~g}^{-1}$, organik asit miktarları ise $\mathrm{mg} \mathrm{kg}^{-1}$ cinsinden ifade edilmiştir.

\section{Fenolik bileşen analizi}

Kayısı meyvesinin fenolik bileşenleri HPLC-DAD (Shimadzu, LC-20AT, Kyoto, Japonya, 2006) ile belirlenmiştir. Toplam fenolik analizi için elde edilen ana stok ekstrakt, $0.45 \mu \mathrm{m}$ gözenek çapına sahip PTFE filtreden geçirildikten sonra enjeksiyon şişesi hazırlanmıştır (Agcam ve Akyıldız, 2015). Kayısı meyvesi fenolik bileşenlerinin tanımlanması sırasında sertifikalı ve yüksek saflıkta standart maddeler kullanılmıştır.

\section{Karotenoid bileşen analizi}

Karotenoid bileşen analizi HPLC-DAD sistemi ile gerçekleştirilmiştir. Bunun için MeléndezMartínez ve ark. (2007) tarafından geliştirilen ekstraksiyon yöntemi temel alınmıştır. Kayısı meyvesi karotenoid bileşenlerinin tanımlanması sırasında sertifikalı ve yüksek saflıkta standart maddeler kullanılmıştır. $\mathrm{Bu}$ standartları oluşturulan kalibrasyon eğrileri piklerin hesaplanmasında kullanılmıştır.

\section{Istatistiksel analizler}

Çalışmada meyve kalite kriterleri 3 yinelemeli olarak yapılmış olup, her yinelemede tek ağaç ve her ağaçtan en az 30 meyve kullanılmıştır. Çeşitlere ait sonuçlar arasındaki farklılık JMP paket programında kullanılarak 't testi' ile karşılaştırılmıştır.

\section{Araştırma Bulguları ve Tartışma}

Kayısı çeşitlerine ait toplam karotenoid, fenolik ve antioksidan aktivitesi

Çalışmada çeşitlere ait insan sağlığı üzerinde önemli etkileri olan toplam karotenoid, fenolik ve antioksidan aktivitesi gibi değerler Çizelge 1'de bildirilmiştir. Bu parametreler açısından çeşitler arasında güçlü düzeyde farklılık olduğu yapılan istatistik analiz sonucunda belirlenmiştir. Teberze çeşidinin incelenen bütün parametreler açısından bariz şekilde üstün olduğu görülmektedir. Bu kapsamda; Sochor ve ark. (2010), 21 tane seçilmiş kayısı çeşidinde antioksidan kapasitesini taze ağırık cinsinden 1.5 ile 142.6 mg TE $100 \mathrm{~g}^{-1}$ olarak, toplam fenol değerini ise 41 ile 170 mg GAE 100g1 olarak belirlemişlerdir. Su ve ark. (2020) ise; çalışmalarında yerel kayısı çeşitlerinde antioksidan aktivitesi değerlerinin 61.72 ile 135.52 mg TEs $100 \mathrm{~g}^{-1}$ arasında olduğunu bildirmişlerdir. Ülkemizde yapılan bir çalışmada ise; Çalışkan ve ark. (2012), Türk çeşitleri, İran-Kafkasya ve Avrupa eko-coğrafik grupların melezlenmesi ile elde edilen hibritler ve Türkiye'nin Akdeniz bölgesinin doğusunda yetiştirilen bazı önemli kayısı çeşitlerinde meyve kalitesi ve fitokimyasal özellikleri iki yıl boyunca incelemişlerdir. Bu çalışmada çeşitlere bağlı olarak taze ağırlık cinsinden fenolik madde miktarları 14.4-177.1 mg GAE $100 \mathrm{~g}^{-1}$, antioksidan aktivitesi ise; 2.3-12.3 mmol $\mathrm{Fe}^{+2} \mathrm{~kg}^{-1}$ düzeyinde değiştiği tespit edilmiştir. Yine ülkemizde yapılan başka bir çalışmada ise, Geçer ve ark. (2020), yabani olarak yetişen kayısı genotiplerinde fenol içeriğinin 34.2 ile $52.8 \mathrm{mg}$ GAE $100 \mathrm{~g}^{-1}$ arasında değiştiğini bildirilmiştir. Çalışmamızda elde edilen sonuçlar literatürle genel olarak uyumlu olmakla birlikte genetik yapının önemi açık şekilde mevcut çalışmada da görülmüştür. Bu bilgilere ek olarak, Hallmann ve ark. (2019), organik olarak yetiştirilen kayısılarda biyolojik olarak aktif olan bileşiklerin (fenoller ve karotenoidler) konvensiyonel olarak yetiştirilenlere kıyasla daha yüksek olduğunu bildirilmiştir. 
Çizelge 1. Kayısı çeşitlerine ait toplam karotenoid, fenolik ve antioksidan aktivitesi değerleri

Table 1. Total carotenoid, phenolic and antioxidant activity values of apricot varieties.

\begin{tabular}{|c|c|c|c|}
\hline & \multicolumn{3}{|l|}{ Çeşit } \\
\hline & \multicolumn{2}{|l|}{ Variety } & \multirow[t]{2}{*}{ thesap } \\
\hline & Ağerik & Teberze & \\
\hline Toplam karotenoid $\left(\mathrm{mg} \mathrm{kg}^{-1}\right)$ & \multirow{2}{*}{$2.78 \mathrm{~b}$} & \multirow{2}{*}{$9.32 \mathrm{a}$} & \multirow{2}{*}{18.2} \\
\hline Total carotenoid $\left(\mathrm{mg} \mathrm{kg}^{-1}\right)$ & & & \\
\hline Toplam fenolik $\left(\mathrm{mg} \mathrm{kg}^{-1}\right)$ & \multirow{2}{*}{$87.3 \mathrm{~b}$} & \multirow{2}{*}{435.4 a } & \multirow{2}{*}{14.0} \\
\hline Total phenolic $\left(\mathrm{mg} \mathrm{kg}^{-1}\right)$ & & & \\
\hline $\begin{array}{l}\text { Antioksidant aktivitesi }\left(\mathrm{mg} \mathrm{TE} \mathrm{kg}{ }^{-1}\right) \\
\text { Antioxidant activity }\left(m g \text { TE } \mathrm{kg}^{-1}\right)\end{array}$ & $335.1 b$ & $1429.1 \mathrm{a}$ & 11.2 \\
\hline $\begin{array}{l}\text { (1): Ortalamalar arasındaki } \\
\text { gösterilmiştir } \\
\text { (2): } t_{\text {cetvel }}=2.78\end{array}$ & farklar & ayrı & lerle \\
\hline
\end{tabular}

Turuncu renkli meyve etine sahip 'Teberze' çeşidinde beklendiği şekilde, beyaz meyve et rengine sahip olan Ağerik'e kıyasla karotenoid içeriğinin daha yüksek olduğu belirlenmiştir. Benzer durum Ruiz ve ark. (2005) tarafından da bildirilmiştir. Flavonoidler bitkilerdeki doğal ürünlerin en büyük ve yaygın grubudur. Bunlar bitki rengine katkı sağlaması yanında birçoğunun aktif antioksidan bileşikler olması nedeniyle insanlar için önemlidir (Rai ve ark., 2016). Bilindiği üzere $\beta$-karoten, $A$ vitaminin öncül maddesidir. Kayısı meyvesinde toplam karotenoidin büyük çoğunluğu $\beta$-karoten'den karşılanmaktadır. Her ne kadar günlük $30 \mathrm{~g}$ alınan kuru kayısının önerilen A vitamini ihtiyacını karşılayabildiği bildirilse de (Drogoudi ve ark., 2008), görüldüğü gibi bu durum tüketilen genotipe bağlı olarak önemli ölçüde değişmektedir. Sonuçlar doğrultusunda ise; turuncu renge sahip olan genotiplerin tüketiciler tarafından yüksek besin içeriğinden dolayı tercih edilmesi önerilmektedir.
Kayısı çeşitlerine asit şeker bileşenleri ve organik asit değerleri

Kayısı çeşitlerine ait meyve tadını etkileyen bireysel şeker ve organik asit değerleri Çizelge 2'de kromatogram görüntüleri ise Şekil 1'de sunulmuştur. Bu kapsamda meyvelerdeki şeker ve organik asit profilinin malik asit dışında oldukça farklı olduğu görülmüştür. Teberze çeşidinde sakaroz ve malik asit dışındaki diğer meyve asitleri önemli ölçüde yüksek iken, Ağerik'de glikoz, fruktoz ve sorbitol'ün sırasıyla 2.95, 0.88 ve $1.91 \mathrm{~g}$ $100 \mathrm{~g}^{-1}$ değerleri ile 'Teberze'ye kıyasla önemli ölçüde yüksek olduğu saptanmıştır.

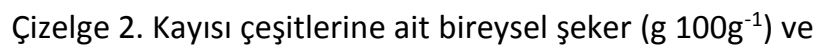
organik asit değerleri $\left(\mathrm{mg} \mathrm{kg}^{-1}\right)$

Table 2. Individual sugar (g $\left.100 \mathrm{~g}^{-1}\right)$ and organic acid values ( $\mathrm{mg} \mathrm{kg}^{-1}$ ) of apricot varieties

\begin{tabular}{|c|c|c|c|}
\hline \multirow{2}{*}{$\begin{array}{l}\text { Bireysel şekerler } \\
\text { Individual sugars }\end{array}$} & \multicolumn{2}{|c|}{$\begin{array}{c}\text { Çeşit } \\
\text { Variety }\end{array}$} & \multirow[t]{2}{*}{$t_{\text {hesap }}$} \\
\hline & Ağerik & Teberze & \\
\hline $\begin{array}{l}\text { Sakaroz } \\
\text { Sucrose }\end{array}$ & $5.33 \mathrm{~b}$ & $8.57 \mathrm{a}$ & 18.5 \\
\hline $\begin{array}{l}\text { Glikoz } \\
\text { Glucose }\end{array}$ & $2.95 \mathrm{a}$ & $1.90 \mathrm{~b}$ & 16.2 \\
\hline $\begin{array}{l}\text { Fruktoz } \\
\text { Fructose }\end{array}$ & $0.88 a$ & $0.60 \mathrm{~b}$ & 12.7 \\
\hline $\begin{array}{l}\text { Sorbitol } \\
\text { Sorbitol }\end{array}$ & $1.91 \mathrm{a}$ & $0.77 \mathrm{~b}$ & 27.4 \\
\hline \multicolumn{4}{|l|}{$\begin{array}{l}\text { Bireysel Asitler } \\
\text { Individual acids } \\
\end{array}$} \\
\hline $\begin{array}{l}\text { Malik Asit } \\
\text { Malic acid }\end{array}$ & 4066.9 & 3888.7 & Ö. D. \\
\hline $\begin{array}{l}\text { Sitrik asit } \\
\text { Citric acid }\end{array}$ & $927.5 \mathrm{~b}$ & $\begin{array}{c}10987.1 \\
a\end{array}$ & 50.4 \\
\hline $\begin{array}{l}\text { Tartarik Asit } \\
\text { Tartaric acid }\end{array}$ & $55.3 \mathrm{~b}$ & $376.4 \mathrm{a}$ & 8.88 \\
\hline $\begin{array}{l}\text { Kuinik Asit } \\
\text { Quinic Acid }\end{array}$ & $763.5 \mathrm{~b}$ & $1123.4 \mathrm{a}$ & 4.47 \\
\hline $\begin{array}{l}\text { Askorbik Asit } \\
\text { Ascorbic acid }\end{array}$ & $1.63 \mathrm{~b}$ & $1.79 \mathrm{a}$ & 2.86 \\
\hline
\end{tabular}

(1): Ortalamalar arasındaki farklar ayrı harflerle gösterilmiştir

(2): Ö.D.: Önemli Değil. $t_{\text {cetvel }}=2.78$

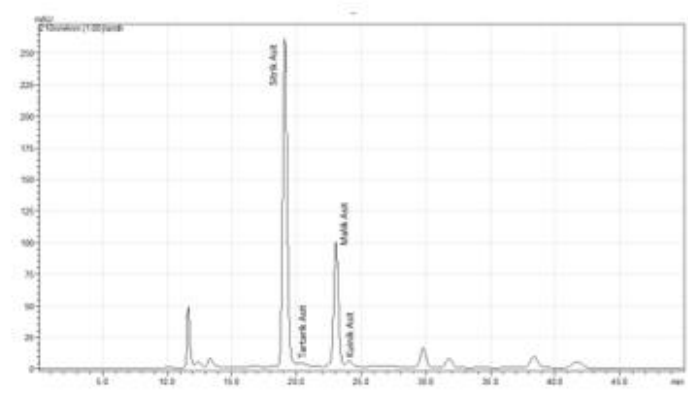

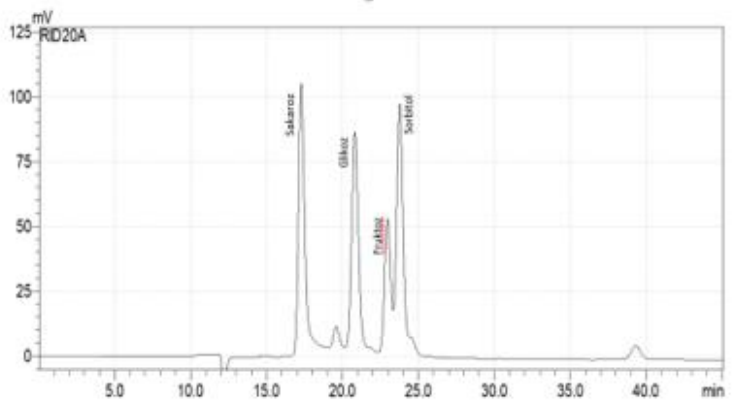

Şekil 1. Yüksek performans sıvı kromatografisinde tespit edilen bireysel şeker ve asit pikleri Figure 1. Individual sugar and acid peaks detected in high performance liquid chromatography 
Kayısı meyveleri temel olarak fruktoz, sorbitol, glikoz ve sakarozdan oluşan 4 temel şekeri içerdiği bildirilmiştir (Fan ve ark., 2017). Çalışmamızla benzer şekilde, İmrak ve ark. (2017), seçilmiş genotipler ve 'Hacıhaliloğlu' çeşidinde taze ağırlık cinsinden en baskın şekerin sakaroz olduğunu bildirmişlerdir. Karataş ve Şengül (2020), sakaroz içeriğinin çeşide göre değişmekle birlikte; 1.83 ile

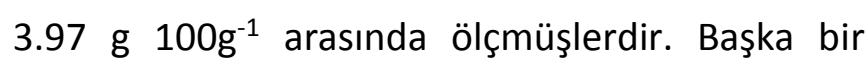
çalışmada ise, Su ve ark. (2020) çalışmalarında yerel kayısı çeşitlerinde baskın şekerin sakaroz ve organik asidin malik asit olduğunu; bunların ise çeşidi göre değişmekle birlikte sırasıyla \%32.9442.49 ve \%69.21-76.75 arasında olduğu belirlenmiştir. Çalışmada yer alan Ağerik'de benzer durum olmasına karşın, Teberze'de baskın asidin sitrik asit olduğu görülmektedir. Naryal ve ark. (2019), çalışmalarında 6 farklı lokasyondan elde edilen 108 genotipte şeker içeriğindeki değişimler incelemiştir. Artan yükseklikle birlikte şeker içeriğinin doğru orantılı $\left(r^{2}=0.877\right)$ arttığı bildirilmiştir. Her yüz metrelik artış sonucunda toplam şeker içeriğinin kuru ağırlık cinsinden 64.8 $\mathrm{mg} \mathrm{g}^{-1}$ arttığını bildirilmiştir. Şeker kompozisyonu incelendiğinde; sakarozun en baskın (\%57.8), bunu glikoz (\% 19.4) ve fruktozun (\%14.3) izlediği, en düşük oranın ise $\% 8.4$ ile sorbitol olduğu bildirilmiştir. Artan yükseklikle birlikte sakaroz ve sorbitol içeriği artarken, fruktoz farklı tepki göstererek azaldığı bildirilmiştir. Görüldüğü gibi şeker ve organik asit kompozisyonu genotipe göre değişmekle birlikte, bakım ve yetiştirme koşullarında bu içerikler üzerine etkili olabileceği görülmüştür. Çalışmamızda, temel organik asitlerin yanında incelenen kayısı çeşitlerinde kuinik, tartarik ve askorbik asitlerde belirlenmiştir. Çalışma sonuçları önceki çalışmalar ile uyumlu olmakla birlikte, genotipin etkisi ve genotip içerisinde şeker ve organik asit kompozisyonunun oldukça farklı olduğu görülmüştür. Sonuç olarak 'Ağerik' çeşidinin düşük organik asit içeriğinden dolayı ile 'Teberze' çeşidine kıyaslandığında tüketildiğinde daha tatlı hissi oluşturacağı belirlenmiştir.

Kayısı çeşitlerine ait bireysel fenolik bileşen içerikleri

Çalışmada çeşitlere ait bazı önemli fenolik maddeler Çizelge 3'te ve Şekil 2'de gösterilmiştir. Beklendiği şekilde toplam fenolik madde içeriğine paralel olarak Teberze çeşidinde kateşin, $p$ kumarik asit ve sinapik asit dışındaki asitlerin istatistiksel açıdan önemli ölçüde yüksek olduğu görülmüştür. Bu fenol bileşiklerin ise iki çeşitte de benzer düzeylerde olduğu tespit edilmiştir.

Çizelge 3. Kayısı çeşitlerine ait bireysel fenolik bileşen içerikleri $\left(\mathrm{mg} \mathrm{kg}^{-1}\right)$

Table 3. Individual phenolic component contents of apricot varieties $\left(\mathrm{mg} \mathrm{kg}^{-1}\right)$

\begin{tabular}{|c|c|c|c|}
\hline \multirow{2}{*}{$\begin{array}{l}\text { Bireysel Fenoller } \\
\text { Individual phenols }\end{array}$} & \multicolumn{2}{|c|}{$\begin{array}{l}\text { Çeşit } \\
\text { Variety }\end{array}$} & \multirow[t]{2}{*}{$t_{\text {hesap }}$} \\
\hline & Ağerik & Teberze & \\
\hline $\begin{array}{l}\text { Gallik Asit } \\
\text { Gallic acid }\end{array}$ & $2.1 \mathrm{~b}$ & 30.9 a & 211 \\
\hline $\begin{array}{l}\text { Vanilik } \\
\text { Vanilic }\end{array}$ & $2.0 \mathrm{~b}$ & $3.4 \mathrm{a}$ & 3.57 \\
\hline $\begin{array}{l}\text { Kateşin } \\
\text { Catechin }\end{array}$ & 11.8 & 16.7 & Ö. D. \\
\hline $\begin{array}{l}\text { Şirinjik } \\
\text { Sirinjik }\end{array}$ & $0.24 b$ & $0.63 a$ & 5.0 \\
\hline $\begin{array}{l}\text { Klorojenik Asit } \\
\text { Chlorogenic Acid }\end{array}$ & $1.15 \mathrm{~b}$ & $7.12 \mathrm{a}$ & 4.44 \\
\hline $\begin{array}{l}p \text {-kumarik Asit } \\
p \text {-coumaric Acid }\end{array}$ & 0.19 & 0.26 & Ö. D. \\
\hline $\begin{array}{l}\text { Sinapik } \\
\text { Synapic }\end{array}$ & 0.19 & 0.17 & Ö. D. \\
\hline $\begin{array}{l}\text { Rutin } \\
\text { Rutin }\end{array}$ & $3.96 \mathrm{~b}$ & $28.4 \mathrm{a}$ & 16.4 \\
\hline $\begin{array}{l}\text { Neo-klorojenik Asit } \\
\text { Neo-chlorogenic Acid }\end{array}$ & $1.0 \mathrm{~b}$ & $8.0 \mathrm{a}$ & 5.25 \\
\hline
\end{tabular}

(1): Ortalamalar arasındaki farklar ayrı harflerle gösterilmiştir

(2): Ö.D.: Önemli Değil. $t_{\text {cetvel }}=2.78$ 

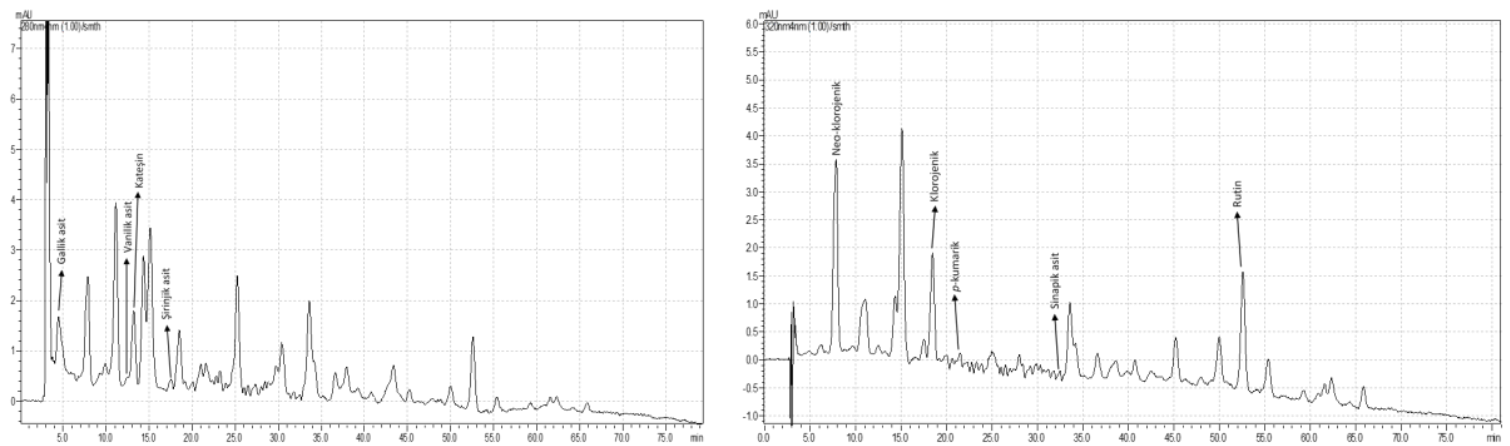

Şekil 2. Yüksek performans sıvı kromatografisinde tespit edilen bireysel fenol pikleri

Figure 2. Individual phenol peaks detected in high performance liquid chromatography

Kayısı meyvelerinde; kafeik asit, ferulik asit, kateşin, epikateşin, $p$-kumarik asit gibi çeşitli fenolik bileşikler tanımlanmıştır (Dragovic-Uzelac ve ark., 2005; Sochor ve ark., 2010). Bu kapsamda Radi ve ark. (1997), kayısıda bulunan; klorojenik ve neo-klorojenik asit, (+)-kateşin, (-)-epikateşin ve rutin (kuersetin-3-rutinosit) 'in temel fenolik bileşikler olduğunu bildirmiştir. Benzer sonuçlar Campbell ve ark. (2013) tarafından da bildirilmiştir. Bu araştırmacılar 5 kayısı çeşidinde kateşin, klorojenik asit ve neo-klorojenik asidin baskın fenolik bileşikler olduğunu tespit etmişlerdir. Başka bir çalışmada Su ve ark. (2020) toplamda 9 adet fenolik bileşik tanımlamışlar, toplam fenolik içeriğinin ise \%50.71 ile 74.05 'ini oluşturan kuercetin-3-rutinozit çeşide bağlı olarak 26.14 ile $60.13 \mathrm{mg} 100 \mathrm{~g}^{-1}$ arasında değiştiğini saptamışlardır. Elde edilen bulgular genel olarak önceki çalışmalarla uyumlu olmakla birlikte, bunların aksine önemli düzeyde gallik asit içeriği tespit edilmiştir. Yerli kayısı çeşitlerinin yer aldığı Gündoğdu ve ark. (2013), çalışmasında kayısı çeşitlerinin erkencilik durumuna göre gallik asit içeriğinin değiştiği, benzer şekilde daha erken dönemde hasat edilen 'Teberze' çeşidinde gallik asit içeriğinin önemli ölçüde yüksek olduğu belirlenmiştir. Bununla birlikte önceki çalışmalarla uyumlu şekilde meyvelerde rutin ve kateşin içeriği tespit edilmiştir. Bu fenolik bileşikler arasında klorojenik ve neo-klorojenik asidin akciğer kanserini önlemede kimyasal önleyici olduğu bildirilmiştir (Noratto ve ark., 2009). Bu bilgiler dâhilinde daha yüksek klorojenik ve neoklorojenik asitleri içeren 'Teberze' çeşidi 'Ağerik'e kıyasla daha ön plana çıkmıştır. Ayrıca, Uğur ve ark. (2018), klorojenik asit düzeyinin güçlü bir şekilde mevsime bağlı olduğunu bildirmiştir. Erken dönemde (Nisan) olgunlaşan meyvelerde, orta (Temmuz) ve geç (Kasım) döneme kıyasla çok daha fazla klorojenik asit olduğu belirlenmiştir. Her ne kadar hasat dönemleri yakın olsa bile çalışmamızda da benzer şekilde daha erkenci (13 gün) olan 'Teberze' çeşidinde klorojenik asit içeriği $7.1 \mathrm{mg} \mathrm{kg}{ }^{-1}$ değeriyle 'Ağerik' çeşidine $(1.2 \mathrm{mg} \mathrm{kg}$ $\left.{ }^{1}\right)$ kıyasla önemli ölçüde yüksek bulunmuştur. Bireysel fenoller üzerine genotipin etkisinin yüksek olması yanında incelen kayısı çeşitlerinde vanilik, şirinjik ve sinapik asit içeriklerinin de oldukça farklı olduğu tespit edilmiştir. Önceki çalışmalarla birlikte genel olarak değerlendirildiğinde hasat olumu daha erken olan çeşitte daha yüksek fenolik madde içeriği tespit edilmiştir.

\section{Kayısı çeşitlerine ait karotenoid bileşen içerikleri}

Çalışmada çeşitlere ait bireysel karotenoid değerleri Çizelge 4'te, bunlara ait kromatogram sonuçları ise Şekil 3’te gösterilmiştir. Bu kapsamda toplam karotenoid içeriğini doğrular nitelikte 'Teberze' çeşidinde bireysel karotenoid değerleri istatistiksel açıdan önemli ölçüde yüksek olduğu belirlenmiştir. Olgunlaşma ile birlikte özellikle toplam karotenoid içeriğinin \%70-85'ini oluşturan 6-karotenin önemli düzeyde arttığı bildirilmiştir (Dragovic-Uzelac ve ark., 2007). Çalışmamızda da benzer şekilde toplam karotenoid içeriğinin büyük çoğunluğunu B-karoten oluşturmaktadır. Bu çalışmada 6-karoten değeri 'Teberze' çeşidinde $269 \mu \mathrm{g} 100 \mathrm{~g}^{-1}$ iken, 'Ağerik' çeşidinde bu değer $73.7 \mu \mathrm{g} 100 \mathrm{~g}^{-1}$ olarak belirlenmiştir. DragovicUzelac ve ark. (2007) ise üç kayısı çeşidinde Bkaroten içeriğini 585.4- $1374.95 \mu \mathrm{g} 100 \mathrm{~g}^{-1}$ olarak belirlemişlerdir. Benzer şekilde 6 -karoten'in temel 
karotenoid olduğu ve bunun toplam karotenoid içeriğinin \%60-70'ini oluşturduğu belirlenmiştir (Radi ve ark., 1997; Ruiz ve ark., 2005; Sass-Kiss ve ark., 2005).

Çizelge 4. Kayısı çeşitlerine ait karotenoid pigment madde değerleri $\left(\mu \mathrm{g} 100 \mathrm{~g}^{-1}\right)$

Table 4. Carotenoid pigment values of apricot varieties $(\mu \mathrm{g}$ $\left.100 \mathrm{~g}^{-1}\right)$

\begin{tabular}{lccc}
\hline \multirow{2}{*}{$\begin{array}{l}\text { Pigment adı } \\
\text { Pigment name }\end{array}$} & \multicolumn{2}{c}{ Çeşit } & \\
\cline { 2 - 3 } & Ağerik & Teberze & \\
\hline lutein & $1.1 \mathrm{~b}$ & $3.5 \mathrm{a}$ & 19.5 \\
zeaksantin & $0.5 \mathrm{~b}$ & $1.8 \mathrm{a}$ & 6.13 \\
6-kriptoksantin & $6.4 \mathrm{~b}$ & $30.5 \mathrm{a}$ & 22.9 \\
13-cis-8-karoten & $3.0 \mathrm{~b}$ & $11.6 \mathrm{a}$ & 26.3 \\
6-karoten & $73.7 \mathrm{~b}$ & $269.1 \mathrm{a}$ & 17.6 \\
9-cis-8-karoten & $4.5 \mathrm{~b}$ & $21.4 \mathrm{a}$ & 29.9 \\
6-kriptoksantin laurat & $0.36 \mathrm{~b}$ & $4.40 \mathrm{a}$ & 18.6 \\
\hline
\end{tabular}

(1): Ortalamalar arasındaki farklar ayrı harflerle gösterilmiştir

(2): Ö.D.: Önemli Değil. $\mathrm{t}_{\text {cetvel }}=2.78$

Bu çalışmalar arasında Ruiz ve ark. (2005), 37 kayısı çeşidinde temel karotenoid pigmentinin 6 - karoten olduğunu, bunu ise 8 -kriptoksantin ve $\gamma$ karoten izlediğini bildirmişlerdir. Mevcut çalışmada da her iki çeşit içinde b-karotenin ardından en yüksek karotenoid pigmentinin Bkriptoksantin olduğu belirlenmiştir. Ayrıca Ruiz ve ark. (2005), çalışmalarında baskın olarak bulunan 8-karoten oranının \%48 (beyaz etli) ile \%88 (turuncu renkli) arasında meyve rengine göre değiştiği saptamışlardır. Diğer karotenoid pigmentlerinden 6 -kriptoksantin turuncu renklilerde \%5 iken sarı renkli kayısılarda \%28 düzeyinde olduğu, diğer pigment $\gamma$-karoten ise turuncu renklilerde $\% 5$ düzeyinde iken, beyaz meyve etine sahip çeşitlerde \%26 düzeyinde olduğunu tespit etmişlerdir. Bunların yanında mevcut çalışmada düşük miktarlarda da olsa 9-cis-6-karoten, 13-cis6-karoten, B-kriptoksantin laurat, lutein ve zeaksantin pigmentleri de her iki çeşitte de belirlenmiştir.

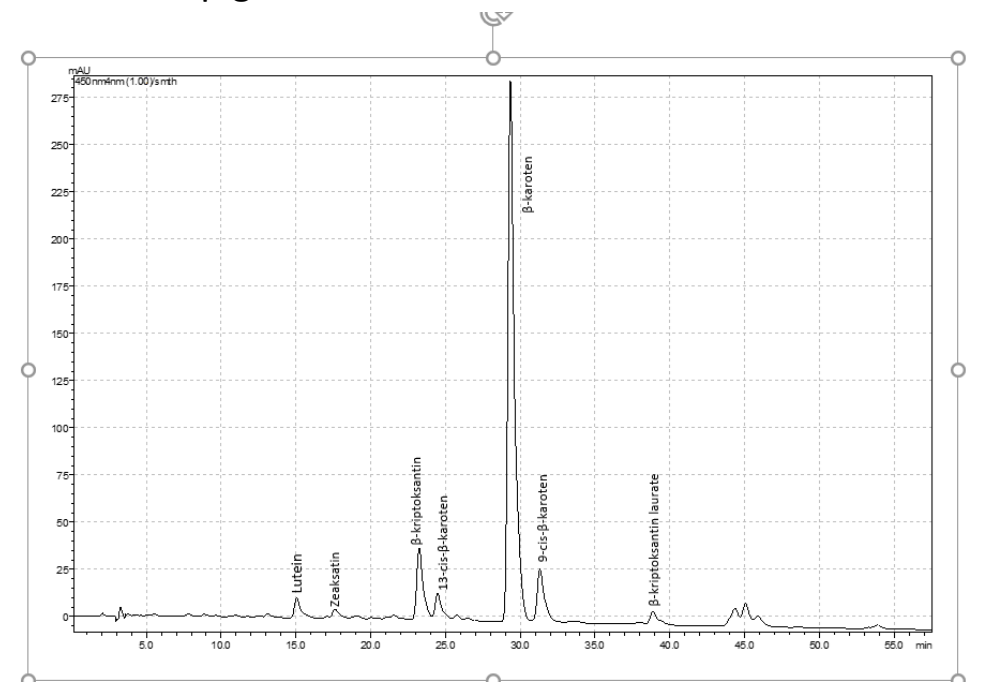

Şekil 3. Yüksek performans sıvı kromatografisinde tespit edilen bireysel karotenoid pikleri Figure 3. Individual carotenoid peaks detected in high performance liquid chromatography

Görüldüğü gibi önceki parametrelerde olduğu gibi karotenoid pigmentlerine ait değerlerde de çeşide özgü önemli düzeyde farklı olduğu belirlenmiştir. Meyve dış rengi turuncu olan 'Teberze' çeşidinin bireysel fenollerde olduğu gibi, karotenoid pigmentler bakımından da zengin olduğu saptanmıştır.

\section{Sonuçlar}

Dünyada kayısı anavatanları içerisinde yer alan ülkemizde çeşitliliğin oldukça yüksek olduğu bilinmektedir. Ülkemizde yetiştiriciliği yapılan çeşitlerin büyük çoğunluğu seleksiyon yöntemiyle elde edilmelerine yanında, son yıllarda farklı meyve özellikleri bünyesinde bulunduran genotiplerin melezlenmesiyle hedefe uygun istenilen özelliklerde çeşit geliştirilmesine yönelik çalışmalar yapılmaktadır. İnsan sağlığı üzerine olumlu etkileri her geçen gün daha iyi anlaşılan meyve antioksidanları ve bunu etkileyen bileşiklerin içeriklerini ortaya çıkaran çalışmaların önemi artmaktadır. Çalışmada yer alan 'Teberze' ve 'Ağerik' Iğdır ilinde Şalak kayısı çeşidinden 
sonra en yüksek miktarda üretimi yapılan önemli kayısı çeşitlerimizdendir. Bu çalışma ile Iğdır iline özgü 'Teberze' ve 'Ağerik' çeşitlerine ait bazı önemli meyve kalite parametreleri ortaya çıkarılmıştır. Yüksek fenolik madde ve antioksidan içeriğinden dolayı 'Teberze' çeşidi besin içeriğini arttırmak amacıyla, yüksek şeker yanında düşük asit içeriği ile meyve tadını geliştirmeye yönelik çalışmalarda 'Ağerik' çeşidi melezleme çalışmalarında genitör olarak kullanılabilir. Her iki çeşitten de aynı miktarlarda tüketilmesi durumunda alınan besin içeriğinin 4 kata kadar farklılık gösterebildiği belirlenmiştir. Bu sebeple günlük besin ihtiyacımızın kayısı miktarından ziyade, tüketilen çeşide bağlı olarak önemli düzeyde değiştiği bu çalışma ile bir kez daha anlaşılmıştır. Meyve renginin tüketiciler için güçlü bir işaret olduğu; turuncu renge sahip (Teberze) çeşitlerde fenolik madde ve buna bağlı olarak antioksidan aktivitenin beyaz renkli meyve etine sahip (Ağerik) çeşide kıyasla yüksek olabileceği görülmüştür. Sonuç olarak ise; bundan sonraki çalışmalarda Ülkemizde yer alan kayısı çeşit veya yabani olarak gelişen seçilmiş genotiplerde benzer çalışmalar yapılarak gen kaynaklarımızın fitokimyasal içerikleri detaylı şekilde ortaya çıkarılması ıslah programları için büyük önem taşımaktadır.

\section{Ekler}

Bu çalışmada yer alan Iğdır yöresine özgü olan çeşitlere ait meyveleri bize gönderdiği için Iğdır Teknik Bilimler Meslek Yüksekokulu Bitkisel ve Hayvansal Üretim Bölümü'nde görev yapan Dr. Öğr. Üye. Eren ÖZDEN' e teşekkür ederiz.

Çıkar Çatışması: Makale yazarları, aralarında herhangi bir çıkar çatışması olmadığını beyan eder.

Yazar Katkısı: MAS çalışmayı tasarlamış, denemeleri kurmuş ve makaleyi yazmış, EA verileri analiz etmiş ve tüm yazarlar çalışmayı birlikte yürütmüştür.

\section{Kaynaklar}

Abdullakasim, P., Songchitsomboon, S., Techagumpuch, M., Balee, N., Swatsitang, P., \& Sungpuag, P. (2007). Antioxidant capacity, total phenolics and sugar content of selected Thai health beverages. International Journal of Food Sciences and Nutrition, 58(1), 77-85. DOI: https://doi.org/10.1080/09637480601140946

Agcam, E., \& Akyıldız, A. (2015). Effects of different solvents and acid concentrations on extraction of anthocyanins from black carrot pomace. GIDAJournal of Food, 40(3), 149-156.

Akpınar, A. E., Koçal, H., Ergül, A., Kazan, K., Şelli, M. E., Bakır, M., Kaymak, S., \& Sarıbaş, R. (2010). SSR-based molecular analysis of economically important Turkish apricot cultivars. Genetics and Molecular Research, 9(1), 324-332.

Altıkat, S., \& Temiz, Ş. (2019). Iğdır İli Kayısı Çeşitlerinin Fiziko-Mekanik ve Bazı Kimyasal Özellikleri. Yüzüncü Yıl Üniversitesi Tarım Bilimleri Dergisi, 29(3), 373381. DOI: https://doi.org/10.29133/yyutbd.521570.

Anonim, (2021). Türkiye İstatistik Kurumu. Retrieved from: https://www.tuik.gov.tr/.

Asma, B. M. (2000). Kayısı Yetistiriciliği. Malatya: Evin Ofset.

Asma, B. M., Karaat, F. E., Çuhacı, Ç., Doğan, A., \& Karaca, H. (2017). Türkiye'de Kayısı Islah Çalışmaları ve Islah Edilen Yeni Çeşitler. Türk Tarım-Gıda Bilim ve Teknoloji Dergisi,5(11), 1429-1438. DOI: https://doi.org/10.24925/turjaf.v5i11.14291438.1292.

Asma, B. M., Murathan, Z. T., Kan, T., Karaat, F. E., Birhanlı, O., \& Erdoğan, A. (2018). 'Eylul': A new late ripening apricot cultivar for fresh market. HortScience, 53(6), 902-903.

DOI: https://doi.org/10.21273/HORTSCI13038-18.

Audergon, J. M. (1993). Variety and breeding. Acta Horticulturae, 384, 35-45.

Bassi, D., Bellini, E., Guerriero, R., Monastra, F., \& Pennone, F. (1993). Apricot breeding in Italy. In $X$ International Symposium on Apricot Culture 384 (pp. 47-54). DOI: https://doi.org/10.17660/ActaHortic.1995.384.3.

Bourguiba, H., Audergon, J. M., Krichen, L., Trifi-Farah, N., Mamouni, A., Trabelsi, S., ... \& Khadari, B. (2012). Loss of genetic diversity as a signature of apricot domestication and diffusion into the Mediterranean Basin. BMC Plant Biology, 12(1), 1-17. DOI: https://doi.org/10.1186/1471-2229-12-49.

Campbell, O. E., Merwin, I. A., \& Padilla-Zakour, O. I. (2013). Characterization and the effect of maturity at harvest on the phenolic and carotenoid content of northeast USA apricot (Prunus armeniaca) varieties. Journal of Agricultural and Food Chemistry, 61(51), 12700-12710. DOI: https://doi.org/10.1021/jf403644r.

Çalışkan, O., Bayazit, S., \& Sumbul, A. (2012). Fruit quality and phytochemical attributes of some apricot (Prunus armeniaca L.) cultivars as affected by genotypes and seasons. Notulae Botanicae Horti Agrobotanici Cluj-Napoca,40(2), 284-294. DOI: https://doi.org/10.15835/nbha4028044.

Çuhacı, Ç., Karaat, F. E., Uğur, Y., Erdoğan, S., \& Asma, B. M. 
(2021). Fruit quality and biochemical characteristics of new early ripening apricots of Turkey. Journal of Food Measurement and Characterization, 15(1), 841850. DOI: https://doi.org/10.1007/s11694-02000685-w.

Dragovic-Uzelac, V., Levaj, B., Mrkic, V., Bursac, D., \& Boras, M. (2007). The content of polyphenols and carotenoids in three apricot cultivars depending on stage of maturity and geographical region. Food Chemistry, 102(3), 966-975.

Dragovic-Uzelac, V., Pospišil, J., Levaj, B., \& Delonga, K. (2005). The study of phenolic profiles of raw apricots and apples and their purees by HPLC for the evaluation of apricot nectars and jams authenticity. Food Chemistry, 91(2), 373-383. DOI: https://doi.org/10.1016/j.foodchem.2004.09.004.

Drogoudi, P. D., Vemmos, S., Pantelidis, G., Petri, E., Tzoutzoukou, C., \& Karayiannis, I. (2008). Physical characters and antioxidant, sugar, and mineral nutrient contents in fruit from 29 apricot (Prunus armeniaca L.) cultivars and hybrids. Journal of Agricultural and Food Chemistry, 56(22), 1075410760. DOI: https://doi.org/10.1021/jf801995x.

Fan, X., Zhao, H., Wang, X., Cao, J., \& Jiang, W. (2017). Sugar and organic acid composition of apricot and their contribution to sensory quality and consumer satisfaction. Scientia Horticulturae, 225, 553-560. DOI: http://doi.org/10.1016/j.scienta.2017.07.016.

Faust, M. (1989). Psysiology of Temperature Zone Fruit Trees. New York: John Wiley and Sons.

Geçer, M. K., Kan, T., Gundogdu, M., Ercisli, S., Ilhan, G., \& Sagbas, H. I. (2020). Physicochemical characteristics of wild and cultivated apricots (Prunus armeniaca L.) from Aras valley in Turkey. Genetic Resources and Crop Evolution, 67(4), 935-945. DOI: https://doi.org/10.1007/s10722-020-00893-9.

Gómez-Martínez, H., Bermejo, A., Zuriaga, E., \& Badenes, M. L. (2021). Polyphenol content in apricot fruits. Scientia Horticulturae, 277, 109828. DOI: https://doi.org/10.1016/j.scienta.2020.109828 .

Gündoğdu, M., Kan, T., \& Gecer, M. K. (2013). Vitamins, flavonoids, and phenolic acid levels in early-and lateripening apricot (Prunus armeniaca L.) cultivars from Turkey. HortScience, 48(6), 696-700. DOI: https://doi.org/10.21273/HORTSCI.48.6.696.

Hallmann, E., Rozpara, E., Słowianek, M., \& Leszczyńska, J. (2019). The effect of organic and conventional farm management on the allergenic potency and bioactive compounds status of apricots (Prunus armeniaca L.). Food Chemistry, 279, 171-178. DOI: https://doi.org/10.1016/j.foodchem.2018.12.018.

Harris, R.S. (1977). Effect of agricultural practices on the content of foods. R.S. Harris, Karmas (Eds.), Nutritional evaluation of food processing, The Avi Publishing Company Inc., Westport, CT (1977), pp. 35-37.

İmrak, B., Küden, A., Yurtkulu, V., Kafkas, E., Ercişli, S., \& Kafkas, S. (2017). Evaluation of some phenological and biochemical characteristics of selected new late flowering dried apricot cultivars. Biochemical Genetics, 55(3), 234-243. DOI: https://doi.org/10.1007/s10528-017-9792-y.

Karataş, N., \& Şengül, M. (2020). Some important physicochemical and bioactive characteristics of the main apricot cultivars from Turkey. Turkish Journal of Agriculture and Forestry, 44(6), 651-661.

Karayiannis, I., Thomidis, T., \& Tsaftaris, A. (2008). Inheritance of resistance to Plum pox virus in apricot (Prunus armeniaca L.). Tree Genetics \& Genomes, 4(2), 143-148. DOI: https://doi.org/10.1007/s11295-007-0095-z.

Karlıdağ, H., Kutsal, İ.K., Karaat, F.E., \& Kan, T. (2021). Bazı organik preparat uygulamalarının Hacıhaliloğlu kayısı çeşidinde meyve dökümü, kalitesi ve verimi üzerine etkileri. Harran Tarım ve Gıda Bilimleri Dergisi. 25(1): 92-99.

DOI:

https://doi.org/10.29050/harranziraat.788317.

Klimczak, I., Małecka, M., Szlachta, M., \& GliszczyńskaŚwigło, A. (2007). Effect of storage on the content of polyphenols, vitamin $\mathrm{C}$ and the antioxidant activity of orange juices. Journal of Food Composition and Analysis, 20(3-4), 313-322. DOI: https://doi.org/10.1016/j.jfca.2006.02.012.

Kostina, K. F. (1960). The use of varietal resources of apricots for breeding. Trud. nikit. bot. Sad.(Trans. Nikita bot. Gdn.)., 40, 45-63.

Ledbetter, C., Peterson, S., \& Jenner, J. (2006). Modification of sugar profiles in California adapted apricots (Prunus armeniaca L.) through breeding with Central Asian germplasm. Euphytica, 148(3), 251-259. DOI: https://doi.org/10.1007/s10681-005-9016-0.

Lee, H. S., \& Castle, W. S. (2001). Seasonal changes of carotenoid pigments and color in Hamlin, Earlygold, and Budd Blood orange juices. Journal of Agricultural and Food Chemistry, 49(2), 877-882. DOI: https://doi.org/10.1021/jf000654r.

Madrau, M. A., Piscopo, A., Sanguinetti, A. M., Del Caro, A., Poiana, M., Romeo, F. V., \& Piga, A. (2009). Effect of drying temperature on polyphenolic content and antioxidant activity of apricots. European Food Research and Technology, 228(3), 441-448. DOI: https://doi.org/10.1007/s00217-008-0951-6.

Meléndez-Martínez, A. J., Vicario, I. M., \& Heredia, F. J. (2007). Provitamin A carotenoids and ascorbic acid contents of the different types of orange juices marketed in Spain. Food Chemistry, 101(1), 177-184. https://doi.org/10.1016/j.foodchem.2006.01.023.

Muradoğlu, F., Pehluvan, M., Gündoğdu, M., \& Tuncay, K. A. Y. A. (2011). Iğdır yöresinde yetiştirilen bazı kayısı genotiplerin fizikokimyasal özellikleri ile mineral içerikleri. Iğdır Üniversitesi Fen Bilimleri Enstitüsü Dergisi, 1(1), 17-22.

Naryal, A., Acharya, S., Bhardwaj, A. K., Kant, A., Chaurasia, O. P., \& Stobdan, T. (2019). Altitudinal effect on sugar contents and sugar profiles in dried apricot (Prunus armeniaca L.) fruit. Journal of Food Composition and Analysis, 76, 27-32. DOI: https://doi.org/10.1016/j.jfca.2018.11.003.

Noratto, G., Porter, W., Byrne, D., \& Cisneros-Zevallos, L. (2009). Identifying peach and plum polyphenols with chemopreventive potential against estrogenindependent breast cancer cells. Journal of Agricultural and Food Chemistry, 57(12), 5219-5226. DOI: https://doi.org/10.1021/jf900259m.

Özyörük, C., Güleryüz, M. (1992). Iğdır ovasında yetişen kayısı çeşitleri üzerinde pomolojik biyolojik ve 
fenolojik araştırmalar. Atatürk Üniversitesi Ziraat Fakültesi Dergisi, 23(1), 16-28.

Radi, M., Mahrouz, M., Jaouad, A., Tacchini, M., Aubert, S., Hugues, M., \& Amiot, M. J. (1997). Phenolic composition, browning susceptibility, and carotenoid content of several apricot cultivars at maturity. HortScience, 32(6), 1087-1091. DOI: https://doi.org/10.21273/HORTSCI.32.6.1087.

Rai, I., Bachheti, R. K., Saini, C. K., Joshi, A., \& Satyan, R. S. (2016). A review on phytochemical, biological screening and importance of Wild Apricot (Prunus armeniaca L.). Oriental Pharmacy and Experimental Medicine, 16(1), $1-15$.

DOI: https://doi.org/10.1007/s13596-015-0215-5.

Ruiz, D., Egea, J., Tomás-Barberán, F. A., \& Gil, M. I. (2005). Carotenoids from new apricot (Prunus armeniaca L.) varieties and their relationship with flesh and skin color.Journal of Agricultural and Food Chemistry, 53(16), 6368-6374. DOI: https://doi.org/10.1021/jf0480703.

Sass-Kiss, A., Kiss, J., Milotay, P., Kerek, M. M., \& TothMarkus, M. (2005). Differences in anthocyanin and carotenoid content of fruits and vegetables. Food Research International, 38(8-9), 1023-1029. DOI: https://doi.org/10.1016/j.foodres.2005.03.014.

Sochor, J., Zitka, O., Skutkova, H., Pavlik, D., Babula, P.,
Krska, B., Horna, A., Adam, V., Provaznik, I., \& Kizek, R. (2010). Content of phenolic compounds and antioxidant capacity in fruits of apricot genotypes. Molecules, 15(9), 6285-6305. DOI: https://doi.org/10.3390/molecules15096285.

Su, C., Zheng, X., Zhang, D., Chen, Y., Xiao, J., He, Y., ... \& Shi, $X$. (2020). Investigation of sugars, organic acids, phenolic compounds, antioxidant activity and the aroma fingerprint of small white apricots grown in Xinjiang. Journal of Food Science, 85(12), 4300-4311. DOI: https://doi.org/10.1111/1750-3841.15523.

Uğur, Y., Erdogan, S., Yilmaz, I., \& Basgel, S. (2018). Variation of quantitative composition of phenolic compounds in the apricot (Prunus armeniaca L.) leaves during the growth seasons. J Nat Prod Plant Resour, 8(1), 33-9.

Yılmaz, K. U., \& Gürcan, K. (2012). Genetic diversity in apricot. In M. Caliskan (Ed.), Genetic Diversity in Plants (pp. 249-270).

Yuan, Z., Chen, X., He, T., Feng, J., Feng, T., \& Zhang, C. (2007). Population genetic structure in apricot (Prunus armeniaca L.) cultivars revealed by fluorescent-AFLP markers in southern Xinjiang, China. Journal of Genetics and Genomics, 34(11), 1037-1047. DOI: https://doi.org/10.1016/S16738527(07)60117-9. 